\title{
Student's Mathematics Anxiety in Solving Mathematical Problems of Logarithms Material
}

\author{
Istifada Nurul Hayati \\ University of Sebelas Maret Surakarta \\ Faculty of Mathematics Education \\ Surakarta, Indonesia \\ kireina.fada@gmail.com
}

\author{
Budiyono \\ University of Sebelas Maret Surakarta \\ Faculty of Mathematics Education \\ Surakarta, Indonesia \\ budiyono53@yahoo.com
}

\author{
Isnandar Slamet \\ University of Sebelas Maret Surakarta \\ Faculty of Mathematics Education \\ Surakarta, Indonesia \\ isnandarslamet@staff.uns.ac.id
}

\begin{abstract}
The process of learning mathematics, anxiety is a supporting and inhibiting factor for student learning achievement, especially in learning logarithm material. Difficulties in the form of anxiety are one of the emotional factors of students. Anxiety can also be a useful stimulus because each student has a different level of anxiety in facing certain material; this can be known and measured by distributed questionnaires the sample class. Anxiety adaptation is a way to overcome anxiety in problem-solving activities. This study aimed to determine the general description of anxiety levels in tenth-grade students (in Roman Numerals $X$ ) dealing with logarithm material. The form of this research is quantitative research. The instrument used was a logarithmic test and a mathematics anxiety questionnaire consisting of 30 statements, which included attitude, somatic, cognitive, and mathematical understanding aspects. The results showed that mathematical anxiety had a very high influence on students' mathematical understanding and mathematics learning abilities. The hope, this research can be used by academics in the world of education to support the success of mathematics learning.)
\end{abstract}

Keywords-Mathematics, Logarithms, Anxiety, Somatic.

\section{INTRODUCTION}

The challenges and development of education in Indonesia in the future will be even greater and more complex. This is due to changes in community demands on the quality and quantity of education. The progress of a country is determined by the development of education in the nation's children so that its quality can be predicted for the future. A plan that is related to the national goals of national education is very influential in obtaining advanced, higher and developing education. In achieving the goals of national education a set of supporting curriculum is needed to be provided to students at the level of the education unit at each level of education.

Benjamin S Bloom, argues that the grouping of educational goals refers to three types of domains or aspects inherent in students, namely (a) Domains of thought processes or cognitive aspects, (b) Domains of attitude values or affective aspects, (c) Domains of skills or psychomotor aspects [1]. These aspects are needed in the learning process, including in learning mathematics. One aspect that is needed in mathematics learning is the affective aspect, which is mathematic anxiety.
Mathematics anxiety is generally defined as feelings of tension and fear of things that interfere with the mathematical performance [2]. Person's previous negative experience strongly influences his future; this mathematics anxiety also becomes a problem in that negative experience [3]. The fact that student' mathematics anxiety levels tend to be high which is a trigger factor for the success of mathematics learning in delivering students to achieve the expected goals. Anxiety can also be a useful stimulus because each student has a different level of anxiety in dealing with certain material. According to K.Cipora, Mathematics anxiety is considered as one of the important factors that contribute to individual achievement in mathematics [4]. Anxiety is considered a positive sign to health, which helps in everyday life, as long as it is a reaction to certain situations, which helps the body to solve specific problems [5]. Mathematics anxiety is the result of several types of problems faced by the person in their daily lives, so that mathematics anxiety is a supporting factor and inhibitor of student learning achievement, especially in learning logarithm material.

Logarithms are material in mathematical subjects that used for practices in further mathematical topics (boundaries, continuity, derivatives, and integrals). Logarithms are one material that is considered quite difficult for some students because there are more properties of logarithms that students must memorize and understand abstractly than direct application to the real world. Data absorption of 2017 National Examination results for Senior High School equivalent in Surakarta in solving mathematical problems related to completing logarithms reached $52.58 \%$ [6], while for 2018 it reached $53.57 \%$ [7].

Related to the absorptive capacity in solving the problem, the logarithm material is low; it can cause anxiety for some students in dealing with mathematics. In accordance with the problems that have been formulated, the purpose of this study is to find a general description of anxiety levels in tenth-grade high school students in Surakarta in solving mathematical problems with logarithm material. Mathematics anxiety is chosen because the components in these aspects support the learning process to be studied so that it can have a positive impact on learning assessment. 


\section{METHOD}

Anxiety adaptation is a way to overcome anxiety in problem-solving activities. Individuals who have mathematics anxiety are characterized by a strong tendency to avoid mathematics, which in turn reduces the math competency itself [5]. The effects of mathematics anxiety can reduce self-confidence, enjoy mathematics less and maybe even avoid math altogether. The form of this research is quantitative [8].

Data collection techniques were an important step when conducting research because the main purposes of conducting research were to obtain data. Data collection techniques can be done by observation, interviews, questionnaires or questionnaires and study documents [9], but in this study data collection technique using (a) observation, according to Sutrisno Hadi observation is one of the processes that complex, a process composed of various biological and psychological processes [10]. All data regarding facts were obtained through observation. Observations in this study were conducted to observe the teacher when the teacher teaches logarithm material and observes students during the process of solving questions and questionnaires given by researchers. At the time of observation, researchers collected all data for research obtained from teachers and students. (b) Tests is a tool or procedure used to find out or measure something in an atmosphere, by means and rules that have been determined. Learning outcomes test is a group of questions or tasks that must be answered or completed by students with the aim of measuring student learning progress.

A test method in this study was seeing students solve mathematical problems. (c) A questionnaire is a data collection technique by written questions to be answered in writing also by respondents. Questionnaire is a collection of written questions that are used to obtain information from respondents about themselves or things they know. Questionnaire in this method used to retrieve data and determine mathematics anxiety faced by students. The questionnaire is subject to reliability analysis which measures the internal consistency of items and item-total correlations.

Testing the reliability of the instrument was using the Cronbach Alpha formula because this study took the form of a questionnaire and a multilevel scale. If the value of alpha > 0.7 means that reliability is sufficient while if alpha $>0.80$ suggests all items are reliable and all tests consistently have strong reliability [11]. The instrument used was an observation sheet, interview guidelines, logarithm problemsolving test questions and a mathematics anxiety questionnaire consisting of 30 statements, which included aspects of attitude, somatic, cognitive, and mathematical understanding.

\section{RESULTS AND DISCUSSION}

The research on students' mathematics anxiety in solving mathematical problems with this material is conducted on 60 students from all tenth-grade high school students in Surakarta and is divided into 30 male and 30 female students using a questionnaire. The questionnaire is subject to reliability analysis which measures the internal consistency of items and item-total correlations. Reliability in the range of 0.70 is acceptable and those with more than 0.80 are good [12]. The reliability analysis is shown in Table 1 where three constructs were found to have good and acceptable reliability.

TABLE 1. RELIABILITY ANALYSIS

\begin{tabular}{lc}
\hline Constructs & Cronbach's Alpha \\
\hline Attitude & 0,895 \\
Somatic & 0,857 \\
Cognitive & 0,868 \\
Mathematical Understanding & 0,873 \\
\hline
\end{tabular}

Based on Table 1 showed that there were 60 students consisting of 30 male students and 30 female students took part in this study, these students were between the ages of 15 and 17 years. The overall situation of the students' attitudes, somatic, cognitive, and mathematical understanding of mathematics will be explained through table 2 with the average student feeling anxious about their attitude towards mathematics subjects' logarithm material followed by somatic factors, cognitive factors, and mathematical understanding factors. This shows the attitude or emotional factors of students playing the most important factors in the process of learning mathematics associated with negative perceptions given to the subject will present low performance among students.

TABLE 2. DESCRIPTIVE STATICS

\begin{tabular}{ccl}
\hline Items & Mean & $\begin{array}{c}\text { Standard } \\
\text { Deviation }\end{array}$ \\
\hline Affective Factors (Attitudes) & 3,8400 & 0,8052 \\
Somatic Factors & 2,9870 & 0,5987 \\
Cognitive Factors (Thinking) & 3,5350 & 0,7134 \\
natical Understanding Factors & 3,6836 & 0,7486 \\
\hline
\end{tabular}

Based on Table 2, students' mathematics anxiety consists of four aspects, namely aspects of attitude consisting of 8 indicators, somatic consisting of 7 indicators, cognitive consisting of 7 indicators, and mathematical understanding consisting of 8 indicators. Each indicator has a minimum score of 1 and a maximum of 5. So that for the somatic and cognitive lowest mathematics anxiety score can be obtained by students is 7 and the mathematics anxiety score is 35 , while for the aspects of attitude and mathematical understanding the lowest mathematics anxiety score can be obtained by students is 8 and the mathematics anxiety score 40. The mathematics anxiety of the four factors combined is then taken on average.

Regression test results between the average mathematics anxiety with the ability to solve mathematical problems of logarithm material for tenth grade students in high school in Surakarta obtained a regression equation $\mathrm{y}^{\hat{}}=179,658$ $2,067 x$ _ 1 value $F=23,226$ and $\mathrm{sig}=0.000$, so it can be concluded that the regression equation is linear or mathematics anxiety has a linear relationship in solving mathematical problems of logarithm material. Mathematics anxiety negatively affects the mathematical problems of logarithm material. Based on the results of the study, mathematic anxiety has a negative relationship in solving mathematical problems of logarithm material. In other words, students who have high mathematics anxiety will have the ability to solve low mathematical problems, and vice versa students who have low mathematics anxiety will have the 
ability to solve high mathematic problems. This is in line with what was expressed by T. Khatoon [13] which mentions mathematics anxiety negatively related to the ability to solve mathematical problems.

\section{CONCLUSION}

The results showed that mathematics anxiety has a linear relationship in solving mathematical problems of logarithm material and has a negative relationship so that if mathematics anxiety is high it results in the ability to solve mathematical problems that are low. It is hoped that this research can be used as a suggestion for teachers to be able to give students an understanding of the importance of solving mathematical problems in daily life so that they can stimulate the spirit of learning mathematics for students.

\section{ACKNOWLEDGEMENT}

This research was supported or partially supported by the University of Sebelas Maret Surakarta. We thank our colleagues from Al-Islam Surakarta High school, Mrs Sugiyanti, S.Pd. who provided insight and expertise that greatly assisted the research, although they may not agree with all of the interpretation or conclusions of this paper.

\section{REFERENCES}

[1] B. Samuel. B, "Taxonomy Of Objective: Cognitive Domain," New York: David Mc. Kay, 1983.

[2] H. Kodal, C. Yazici, and V. Yazici, "Mathematics anxiety of secondary school students : A case study for Kocaeli area," Procedia - Soc. Behav. Sci., vol. 152, pp. 630-636, 2014.

[3] Cartioglu, H., Gurbuz, R., and Birgin, O, "Do preservice elementary school teacher still have mathematics anxiety? some factors and correlates," Bolema, vol. 28, no. 48, pp. 110-127, 2014.
[4] K. Cipora, M. Szczygiel, K. Willmes, and H. C. Nuerk, "Math anxiety assessment with the Abbreviated Math Anxiety Scale: Applicability and usefulness: Insights from the polish adaptation," Front. Psychol., vol. 6, no. NOV, pp. 1-16, 2015.

[5] C. Salavera, J. L. Antoñanzas, R. Noé, and P. Teruel, "Emotion and anxiety in teachers, research of teaching physical education," Procedia - Soc. Behav. Sci., vol. 132, pp. 577-581, 2014.

[6] Badan Standar Nasional Pendidikan. "Prosedur Operasional Standar Penyelenggaran Ujian Nasional Tahun Pelajaran 2016/2017". Jakarta, BSNP, 2017.

[7] _ Prosedur Operasional Standar Penyelenggaran Ujian Nasional Tahun Pelajaran 2017/2018". Jakarta, BSNP, 2018.

[8] F. Hill, I. C. Mammarella, A. Devine, S. Caviola, M. Chiara, and D. Sz, "Maths anxiety in primary and secondary school students: Gender differences, developmental changes and anxiety specificity," no. 2015, 2016.

[9] S. Wu, Samuel and Chen, Shigang and Bhattacharjee, Abhishek and He, Yin, "Collusion Resistant MultiMatrix Masking for Privacy-Preserving Data Collection," 1-7. 10.1109/BigDataSecurity, 10, 2017.

[10] Sugiyono, "Metode Penelitian Kuantitatif, Kualitatif dan R\&D," Bandung: Alfabet, 2016.

[11] A. Wieland, C. Durach,. et all, "Statistical and judgmental criteria for scale purification," Supply Chain Management, 2017.

[12] U, Sekaran and Bougie, R, "Metode Penelitian untuk Bisnis," Jakarta: Salemba Empat, 2017.

[13] Khatoon, T and Mahmood, S., "Mathematics anxiety among secondary school students in India and its relationship to achievement in mathematics," European Journal of Social Sciences. 16. 75-86, 2010. 